\title{
Portfel dwuskładnikowy z wartością bieżącą daną liczbą rozmytą o skończonym nośniku
}

Joanna Siwek*

\section{Wprowadzenie}

Pomimo że istniejące modele portfela instrumentów finansowych pozwalają na uwzględnienie ryzyka niepewności przyszłych zwrotów oraz pomimo możliwości minimalizowania ryzyka niepewności tych zwrotów, inwestowanie w portfel efektywny nadal nie gwarantuje osiągnięcia zysku. Wybierając portfele minimalizujące ryzyko niepewności, inwestor nadal odczuwa istnienie pewnego rodzaju ryzyka, które ma wpływ na jego decyzje.

Ryzyko to nazywać będziemy ryzykiem rezydualnym. Jednym ze składników ryzyka rezydualnego jest ryzyko nieprecyzyjności, związane z nieprecyzyjnością informacji wykorzystywanej w podejmowaniu decyzji. Za Klirem (1993) jako nieprecyzyjność informacji rozumie się powszechnie jej nieostrość oraz wieloznaczność. Wieloznaczność interpretujemy jako brak jednoznacznego wyróżnienia pomiędzy rekomendowaną alternatywą a pozostałymi możliwościami decyzyjnymi. Nieostrość informacji interpretujemy natomiast jako brak jednoznacznego rozróżnienia pomiędzy daną informacją a jej zaprzeczeniem. Tym samym na ryzyko nieprecyzyjności składają się ryzyka wieloznaczności i nieostrości.

Wzrost ryzyka wieloznaczności oznacza wzrost ilości alternatywnych rekomendacji inwestycyjnych. Powoduje to wzrost ryzyka podjęcia decyzji finansowej, która ex post zostanie obarczona stratą utraconych szans. Wzrost ryzyka nieostrości oznacza zacieranie się granic wyróżniających rekomendowane alternatywy inwestycyjne. Powoduje to groźbę wyboru alternatywy nierekomendowanej.

* Joanna Siwek, Uniwersytet Ekonomiczny w Poznaniu, Katedra Badań Operacyjnych, joanna.siwek@ue.poznan.pl 
Dotychczasowy stan wiedzy w rozważanej tematyce ma swoje źródło w pracy Warda (1985), który definiuje wartość bieżącą jako zdyskontowany rozmyty przepływ pieniężny. Kontynuując jego pracę, Calzi (1990) uogólnił tę definicję na przypadek rozmyty. Dalsze prace nad zdefiniowaniem PV zaowocowały definicją uogólnioną na przypadek rozmytej duracji przez Greenhuta i innych (1995).

Buckley (1987,), Gutierrez (1989) oraz Kuchta (2000) i Lesage (2001) badali zastosowanie arytmetyki rozmytej do wyznaczania wartości bieżącej. Huang (2007) uogólnia tymczasem definicję Warda dla przypadku, kiedy przyszłe przepływy pieniężne dane są w postaci rozmytej zmiennej losowej. W 2005 roku Tsao wprowadził nową, jeszcze ogólniejszą definicję wartości bieżącej (Tsao 2005), zakładającą, że przyszły przepływ pieniężny jest rozmytym zbiorem probabilistycznym.

Piasecki (2011) zauważył, że - ze względu na nieprecyzyjność wyznaczenia wartości bieżącej oraz traktowanie wartości przyszłej jako zmiennej losowej - możliwe jest przedstawienie stopy zwrotu $\mathrm{z}$ instrumentu jako rozmytego zbioru probabilistycznego. Zaproponowany model nie tylko uwzględnia problem nieprecyzyjności, ale również wskazuje na istnienie niepewności obarczającej instrument. W artykule Piaseckiego i Siwek (2015) zbadany został wpływ przesłanek behawioralnych i nieprecyzyjności na decyzje podejmowane przez inwestorów. W publikacjach Siwek (2015 a, b) przeprowadzono analizę ryzyka portfela dwuskładnikowego w przypadku instrumentów składowych z wartością bieżącą daną trójkątną i trapezoidalną liczbą rozmytą.

W poniższej pracy bardziej niż na opisie niepewności zwrotu skupiono się na opisaniu ryzyka nieprecyzyjności wartości bieżącej. Powodem powyższego założenia jest fakt, że rozważana wartość bieżąca ma charakter subiektywny oraz nie ulega weryfikacji w przyszłości. Dlatego trudno określić, czy wartość ta dobrze odzwierciedlała wartość instrumentu w danym momencie. Ponadto nie sposób otrzymać liczbowej realizacji tej wartości w przyszłości, nawet na moment wyznaczenia stopy zwrotu z portfela. Tym samym wartość bieżąca nie spełnia warunków potrzebnych dla istnienia prawdopodobieństwa, niezależnie, czy są to warunki określone przez Knighta (1964), von Missesa (1957), Caplana (2001), Kołmogorowa (1956), Sadowskiego (1980) czy Czerwińskiego (1960).

Pojęcie dyskretnej liczby rozmytej, jako szczególny przypadek wprowadzonych przez Zadeha (1965) zbiorów rozmytych, wprowadził Voxman (2001). Arytmetyka tego typu liczb rozmytych była badana m.in. przez Guixiang Wang i Cheng Lin Wen (2007) oraz Guixiang Wang, Qing Zhang i Xianjun Cui (2008). Natomiast Vicente Riera i Torrens $(2014,2015)$ zastosowali skończone liczby rozmyte do modelowania niekompletnej informacji ilościowej.

Miary energii dla zbiorów rozmytych, w szczególności dla liczb rozmytych o skończonym nośniku, badane były m.in. przez Czogałę, Gottwalda, Pedrycza (1982). Natomiast prace nad miarami entropii skończonych liczb rozmytych były prowadzone przez De Lucę, Terminiego (1972), Dumitrescu (1993), Wenyi Zeng, Qilei Feng, Hong Xing Li (2006). 


\section{Uogólnione liczby rozmyte}

Poniższa definicja liczby rozmytej została wprowadzona i rozpowszechniona przez Dubois i Pradego (1980). Definicja ta może być rozszerzona do przypadku uogólnionych liczb rozmytych. Uogólniona liczba rozmyta $\mathcal{R}$ to rozmyty podzbiór $\mathbb{S}(\mathcal{R}) \subset \mathbb{R}$ określony przez swoją funkcję przynależności $\mu_{\mathcal{R}}: \mathbb{S}(\mathcal{R}) \rightarrow[0,1] \mathrm{z}$ następującymi ograniczeniami:

$$
\begin{gathered}
\exists_{x \in \mathbb{S}(\mathcal{R})}: \mu_{\mathcal{R}}(x)=1 \\
\forall_{(x, y, z) \in \mathbb{S}(\mathcal{R})^{3}}: x \leq y \leq z \Rightarrow \mu_{\mathcal{R}}(y) \geq \min \left\{\mu_{\mathcal{R}}(x), \mu_{\mathcal{R}}(z)\right\}
\end{gathered}
$$

Zbiór $\mathbb{S}(\mathcal{R})$ jest nazywany nośnikiem uogólnionej liczby rozmytej $\mathcal{R}$.

Rozważmy teraz parę uogólnionych liczb rozmytych $(\mathcal{Q}, \mathcal{R})$ wraz z ich odpowiadającymi funkcjami przynależności $\mu_{\mathcal{Q}}: \mathbb{S}(\mathcal{Q}) \rightarrow[0,1]$ i $\mu_{\mathcal{R}}: \mathbb{S}(\mathcal{R}) \rightarrow[0,1]$.

Zgodnie z zasadą rozszerzenia Zadeha suma $\mathcal{Q} \oplus \mathcal{R}$ jest również uogólnioną liczbą rozmytą opisaną funkcją przynależności $\mu_{\mathcal{Q}+\mathcal{R}}: \mathbb{S}(\mathcal{Q}+\mathcal{R}) \rightarrow[0,1]$, gdzie:

$$
\begin{gathered}
\mathbb{S}(\mathcal{Q}+\mathcal{R})=\left\{z \in \mathbb{R}: \exists_{(x, y) \in \mathbb{S}(\mathcal{Q}) \times \mathbb{S}(\mathcal{R})}: z=x+y\right\} \\
\mu_{\mathcal{Q}+\mathcal{R}}(z)=\max \left\{\min \left\{\mu_{\mathcal{Q}}(x), \mu_{\mathcal{R}}(y)\right\}\right\},(x, y) \in \mathbb{S}(\mathcal{Q}) \times \mathbb{S}(\mathcal{R}), z=x+y
\end{gathered}
$$

Podobnie przemnożenie uogólnionej liczby rozmytej $\mathcal{R}$ przez skalar $r \in \mathbb{R}^{+}$definiujemy jako iloczyn $\mathrm{r} \otimes \mathcal{R}$ opisany funkcją przynależności $\mu_{\mathrm{r} \otimes \mathcal{R}}: \mathbb{S}(\mathrm{r} \cdot \mathcal{R}) \rightarrow[0,1]$, gdzie:

$$
\begin{gathered}
\mathbb{S}(r \cdot \mathcal{R})=\left\{z \in \mathbb{R}: \exists_{y \in \mathbb{S}(\mathcal{R})}: z=r \cdot y\right\} \\
\mu_{r \cdot \mathcal{R}}(z)=\mu_{\mathcal{R}}\left(\frac{z}{r}\right) .
\end{gathered}
$$

Rozważane w tym artykule dyskretne liczby rozmyte, które zostały po raz pierwszy wprowadzone przez Voxmana (2001), mogą być traktowane jako podprzypadek uogólnionych liczb rozmytych $\mathcal{R}$, gdzie nośnik jest zbiorem skończo$\operatorname{nym} \mathbb{S}(\mathcal{R})=\left\{\mathrm{x}_{1}^{\mathcal{R}}, \mathrm{x}_{2}^{\mathcal{R}}, \ldots, \mathrm{x}_{\mathrm{n}_{\mathcal{R}}}^{\mathcal{R}}\right\}$.

Ze względu na trendy występujące w literaturze przedmiotu, wprowadzone zostaną definicje trapezoidalnych i trójkątnych dyskretnych liczb rozmytych.

Trapezoidalna uogólniona liczba rozmyta, jako szczególny przypadek uogólnionej liczby rozmytej oraz zgodnie z definicją podaną w publikacji Dubois i Pradego 
(1980), to czwórka $T(a, b, c, d)$ określająca uogólnioną liczbę rozmytą z funkcją przynależności daną wzorem u: $\mathrm{S}(T(a, b, c, d)) \rightarrow[0,1]$ :

$$
\mu_{T}(x \mid a, b, c, d)=\left\{\begin{array}{lrc}
\frac{x-a}{b-a}, & \text { dla } & a \leq x \leq b \\
1, & \text { dla } & b<x<c \\
\frac{x-d}{c-d}, & \text { dla } & c \leq x \leq d
\end{array}\right.
$$

Trapezoidalna uogólniona liczba rozmyta to podprzypadek trapezoidalnej uogólnionej liczby rozmytej, gdzie $b=c$, ozn. $T(a, b, c)$.

Kierując się analogią, trapezoidalna dyskretna liczba rozmyta stanowi podprzypadek dyskretnej liczby rozmytej i analogicznie jak w Voxman (2001) definiujemy ją jako czwórkę $D T(a, b, c, d)$ z nośnikiem $S(D T(a, b, c, d))=$ $=\left\{x_{1}, x_{2}, \ldots, x_{n}\right\}$ oraz funkcją przynależności $\mu: \mathbb{S}(\mathcal{R}) \rightarrow[0,1]$, taką że dla dowolnego $x_{k} \in\left\{x_{1}, x_{2}, \ldots, x_{n}\right\}$ :

$$
\mu_{D T}\left(x_{k} \mid a, b, c, d\right)=\left\{\begin{array}{lcc}
\frac{x_{k}-a}{b-a}, & \text { dla } & a \leq x_{k} \leq b \\
1, & \text { dla } & b<x_{k}<c \\
\frac{x_{k}-d}{c-d}, & \text { dla } & c \leq x_{k} \leq d
\end{array} .\right.
$$

Trapezoidalna uogólniona liczba rozmyta to podprzypadek trapezoidalnej uogólnionej liczby rozmytej gdzie $b=c$, ozn. $D T(a, b, c)$.

\section{Model dyskretnej wartości bieżącej}

Rozważmy dowolny instrument finansowy $A \mathrm{z}$ wartością bieżącą $P V$ daną dyskretną liczbą rozmytą, reprezentowaną przez swoją funkcję przynależności $\mu: \mathbb{R} \rightarrow[0,1]$. Wartość przyszła tego instrumentu opisana jest zmienną losową $\tilde{\mathrm{V}}: \Omega=\{\omega\} \rightarrow \mathbb{R}$.

Nośnik $P V$ dany jest jako:

$$
\mathbb{S}(P V)=\left\{x_{1}, x_{2}, \ldots, x_{n}\right\}, x_{1}<x_{2}<\ldots<x_{n}
$$

Dla danego momentu w czasie $t \in T$ oraz przy założeniu prostych stóp zwrotu $r \in \mathbb{R}$, funkcja przynależności $\mu: \mathbb{R} \rightarrow[0,1]$ rozmytego zwrotu $\mathrm{z}$ instrumentu $(R)$ dana jest następującą formułą: 


$$
\rho(r, \omega)=\max \left(\mu\left(x_{i}\right): r=\frac{V_{t}(\omega)-x_{i}}{x_{i}}\right)=\mu\left(\frac{V_{t}(\omega)}{1+r}\right)
$$

gdzie $x_{i} \in\left\{x_{1}, x_{2}, \ldots, x_{n}\right\}$. Nośnik stopy zwrotu z portfela $(R)$ dany jest wzorem:

$$
\mathbb{S}(R)=\left\{r \in \mathbb{R}: \exists x_{i} \in \mathbb{S}(P V): r=\frac{V_{t}(\omega)-x_{i}}{x_{i}}\right\}
$$

Tak określony zwrot z instrumentu o wartości bieżącej danej dyskretną liczbą rozmytą o skończonym nośniku jest również dyskretną liczbą rozmytą o skończonym nośniku.

W niniejszym artykule jako miarę niejednoznaczności zwrotu z instrumentu zastosujemy energię. Zgodnie z pozycją (Czogała, Gottwald, Pedrycz 1982) dla dowolnego instrumentu, z którego zwrot dany jest liczbą rozmytą o skończonym nośniku, dana jest ona wzorem:

$$
\delta(R)=\sum_{r \in \mathbb{S}(R)} \rho(r)
$$

Jako miarę nieostrości zwrotu z instrumentu zastosujemy tymczasem entropię. Dla dowolnego instrumentu, z którego zwrot dany jest liczbą rozmytą o skończonym nośniku, wynosi ona:

$$
\varepsilon(R)=\sum_{r \in \mathbb{S}(R)} \min (\rho(r), 1-\rho(r))
$$

\section{Budowa i własności portfela}

Proponowany model opiera się na podanym przez Piaseckiego (2011) modelu nieprecyzyjnej stopy zwrotu i nawiązuje do Markowitza (1952) z następującymi modyfikacjami:

- przyjmujemy proste stopy zwrotu:

$$
r_{t}=\frac{V_{t}-V_{0}}{V_{0}}
$$

- wartość przyszła jest zmienną losową o rozkładzie normalnym,

- wartość bieżąca jest reprezentowana przez liczbę rozmytą o skończonym nośniku.

Weźmy dwa dowolne instrumenty finansowe $A$ i $B$, o wartościach bieżących $P V_{A}$ i $P V_{B}$, danych liczbami rozmytymi o skończonym nośniku, reprezentowanymi przez funkcje przynależności $\mu_{A}: X \rightarrow[0,1]$ i $\mu_{B}: X \rightarrow[0,1]$. Wtedy, zgodnie 
$\mathrm{z}$ zasadą rozszerzania Zadeha, funkcja przynależności $\mu: X \rightarrow[0,1]$ do zboru rozmytego $P V$, odpowiadającego wartości bieżącej portfela złożonego z tych instrumentów, ma postać:

$$
\mu(x)=\mu_{P V_{A} \oplus P V_{B}}(x)=\max _{\substack{x=x_{i}^{A}+x_{j}^{B}, x_{i}^{A} \in S\left(P V_{A}\right), x_{j}^{B} \in S\left(P V_{B}\right)}} \min \left(\mu_{A}\left(x_{i}^{A}\right), \mu_{B}\left(x_{j}^{B}\right)\right)
$$

gdzie: $x \in \mathbb{S}(P V)$ i nośnik $P V$ dany jest zbiorem:

$$
\begin{gathered}
\mathbb{S}(P V)=\left\{x_{1}, x_{2}, \ldots, x_{m}\right\}= \\
=\left\{x_{k} \in \mathbb{R}: x_{k}=x_{i}^{A}+x_{j}^{B}, x_{i}^{A} \in \mathbb{S}\left(P V_{A}\right), x_{j}^{B} \in \mathbb{S}\left(P V_{B}\right)\right\} .
\end{gathered}
$$

Tak zdefiniowana wartość bieżąca portfela spełnia założenia dyskretnej liczby rozmytej.

Przy założeniu prostych stóp zwrotu przynależność do zbioru rozmytego, odpowiadającego zwrotowi z portfela, dana jest wzorem:

$$
\begin{gathered}
\rho(r, \omega)=\max \left(\mu\left(x_{i}\right): r=\frac{V_{t}(\omega)-x_{i}}{x_{i}}\right)=\mu\left(\frac{V_{t}(\omega)}{1+r}\right)= \\
=\max _{\substack{x=x_{i}^{A}+x_{j}^{B}, x_{i}^{A} \in S\left(P V_{A}\right), x_{i}^{B} \in S\left(P V_{B}\right)}} \min \left(\mu_{A}\left(x_{i}^{A}\right), \mu_{B}\left(x_{j}^{B}\right)\right)
\end{gathered}
$$

gdzie: $x_{i} \in \mathbb{S}(P V)$.

Nośnik liczby rozmytej odpowiadającej oczekiwanemu zwrotowi z portfela ma postać:

$$
\mathbb{S}(R)=\left\{r \in \mathbb{R}: \exists x_{i \in \mathbb{S}(P V)} r=\frac{V_{t}(\omega)-x_{i}}{x_{i}}\right\}
$$

Tak określony zwrot z portfela jest również dyskretną liczbą rozmytą.

Dla krótszego zapisu przyjmijmy oznaczenie:

$$
M=\max _{\substack{x=x_{i}^{A}+x_{j}^{B}, x_{i}^{A} \in S\left(P V_{A}\right), x_{i}^{B} \in S\left(P V_{B}\right)}} \min \left(\mu_{A}\left(x_{i}^{A}\right), \mu_{B}\left(x_{j}^{B}\right)\right)
$$


Energia dla portfela przyjmuje postać:

$$
\delta(R)=\sum_{r \in \mathbb{S}(R)} \rho(r)=\sum_{r \in \mathbb{S}(R)} \mathrm{M} .
$$

Entropia dla portfela przyjmuje postać:

$$
\varepsilon(R)=\sum_{r \in \mathbb{S}(R)} \min (M, 1-M) .
$$

Można sprawdzić, że zależności pomiędzy energią i entropią dla poszczególnych instrumentów oraz dla instrumentów i portfela mogą mieć postać:

$$
\begin{gathered}
\delta(R) \geq \min \left(\delta_{1}(R), \delta_{2}(R)\right) \\
\varepsilon(R) \geq \min \left(\varepsilon_{1}(R), \varepsilon_{2}(R)\right)
\end{gathered}
$$

\section{Studium przypadku}

W programie Matlab przeprowadzono symulacje zachowania portfela w przypadku dwóch instrumentów składowych, których wartości bieżące dane są za pomocą dyskretnych liczb rozmytych. Przyjęto następujące dane:

- wartość bieżąca instrumentu $A$ dana jest dyskretną trójkątną liczbą rozmytą DT(78, 80, 82),

- zmienna losowa odpowiadająca wartości przyszłej instrumentu $A$ dana jest rozkładem normalnym o parametrach $N(100,4)$,

- wartość bieżąca instrumentu $B$ dana jest dyskretną trapezoidalną liczbą rozmytą $D T(69,70,72,75)$,

- zmienna losowa odpowiadająca wartości przyszłej instrumentu $B$ dana jest rozkładem normalnym o parametrach $N(90,2)$,

- jednostka dyskretyzacji wynosi 0,0001.

Interpretacja podanych parametrów została wyjaśniona w Siwek (2015a).

Funkcje przynależności do zbioru rozmytego odpowiadającego wartości bieżącej instrumentów $A$ i $B$, zwroty dla tych instrumentów (10), funkcje przynależności do wartości bieżącej portfela (15) oraz liczba rozmyta odpowiadającaoczekiwanemu zwrotowi z portfela (17) przedstawione są na rysunkach poniżej. 

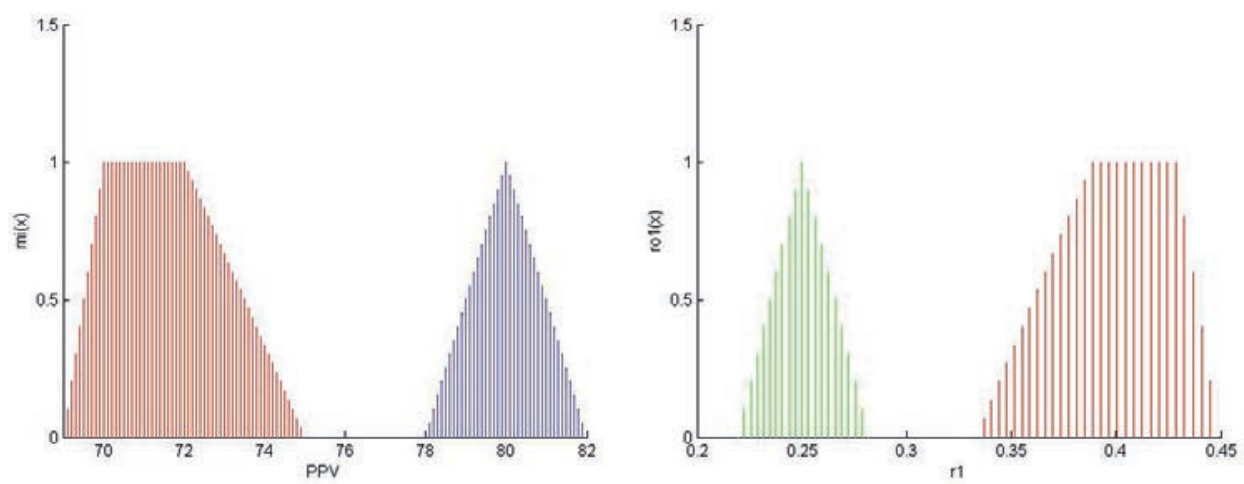

Wykres 1. Po lewej: wartości bieżące instrumentów $\boldsymbol{A}$ i $\boldsymbol{B}$. Po prawej: oczekiwane zwroty z instrumentów $\boldsymbol{A}$ i $\boldsymbol{B}$

Źródto: opracowanie własne.
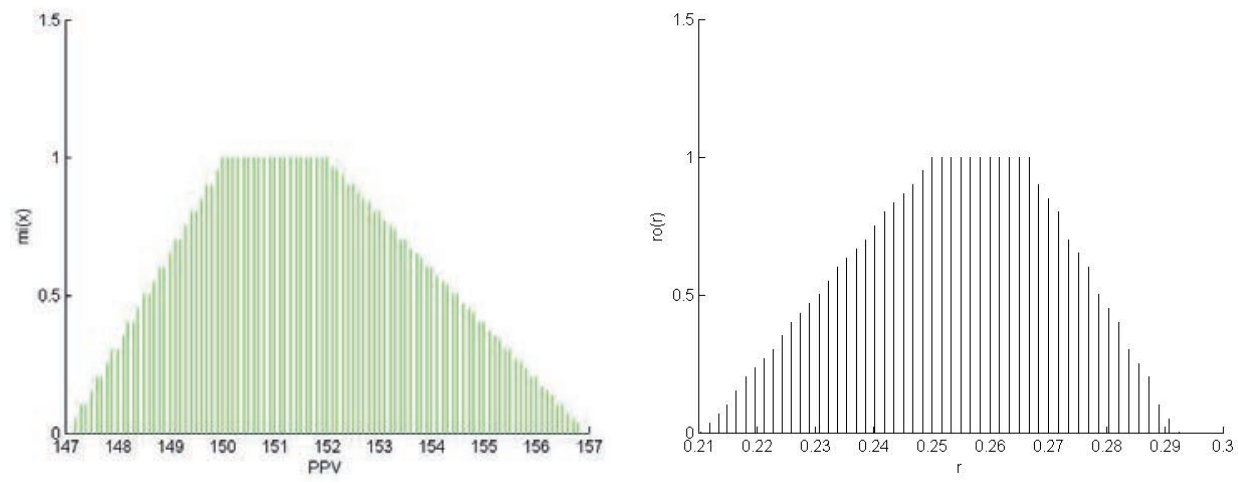

Wykres 2. Po lewej: wartość bieżąca portfela. Po prawej: Oczekiwany zwrot z portfela Źródto: opracowanie własne.

W wyniku symulacji, zgodnie ze wzorami (20), (21) otrzymano następujące wyniki dla energii i entropii portfela i jego składników.

Tabela 1. Wyniki symulacji miar ryzyka dla badanych instrumentów oraz złożonego z nich portfela

\begin{tabular}{|l|c|c|c|}
\hline Instrument, miara & $\boldsymbol{A}$ & $\boldsymbol{B}$ & Portfel \\
\hline Energia & 20,02 & 40,02 & 934,24 \\
\hline Entropia & 10,01 & 10,01 & 601,04 \\
\hline
\end{tabular}

Źródto: opracowanie własne.

W wyniku symulacji otrzymano zatem następujące zależności:

$$
\begin{aligned}
& \delta>\delta_{A}>\delta_{B} \\
& \varepsilon>\varepsilon_{A}=\varepsilon_{B}
\end{aligned}
$$




\section{Podsumowanie}

Na podstawie przeprowadzonych rozważań teoretycznych ustalono, że w przypadku wartości bieżących instrumentów, uwzględniających ryzyko nieprecyzyjności i wyrażonych liczbami rozmytymi o skończonym nośniku, ryzyko to nie może być traktowane w sposób jednorodny. Otrzymano, że konstrukcja portfela:

- może spowodować zwiększenie ryzyka niejednoznaczności informacji,

- może spowodować zwiększenie ryzyka nieostrości informacji.

Oznacza to, że dywersyfikacja portfela dwuskładnikowego nie powoduje zmniejszenia badanych rodzajów ryzyka, co może wskazywać na nieoptymalność stosowania tej metody i konieczność stworzenia nowego zadania minimalizacji ryzyka i maksymalizacji zysku.

Otrzymane wyniki wskazują na celowość przeprowadzonych badań i zachęcają do ich kontynuacji. Celowe dla całkowitego opisania badanego zjawiska może być przeprowadzenie badań dla portfela o ograniczonym nośniku wartości bieżącej instrumentów oraz uogólnienie wyników dla większej liczby aktywów.

Projekt został sfinansowany ze środków Narodowego Centrum Nauki przyznanych na podstawie decyzji numer DEC-2015/17/N/HS4/00206.

\section{Bibliografia}

Buckley I.J. (1987), The fuzzy mathematics of finance, Fuzzy Sets and Systems, Vol. 21, p. 267-273.

Calzi M.L. (1990), Towards a general setting for the fuzzy mathematics of finance, Fuzzy Sets and Systems, Vol. 35, p. 265-280.

Caplan B. (2001), Probability, common sense, and realism: a reply to Hulsmann and Block, The Quarterly Journal of Austrian Economics, Vol. 4, No. 2, p. 69-86.

Casasnovas J., Vicente Riera J. (2006), On the addition of discrete fuzzy numbers, Proceedings of the 5th WSEAS International Conference on Telecommunications and Informatics, Istanbul, Turkey, May 27-29, p. 432-437.

Czerwiński Z. (1960), Enumerative induction and the theory of games, Studia Logica, Vol. 10, p. 29-38.

Czogała E., Gottwald S., Pedrycz W. (1982), Contribution to application of energy measure of fuzzy sets, Fuzzy Sets and Systems, Vol. 8, North-Holland Publishing Company, p. 205-214.

De Luca A., Termini S. (1972), A definition of non-probabilistic entropy in the setting of fuzzy set theory, Information and Control, Vol. 20, p. 301-312.

Dubois D., Prade H. (1980), Fuzzy Sets and Systems: Theory and Applications, Mathematics in Science and Engineering, Vol. 144.

Dumitrescu D. (1993), Fuzzy measures and the entropy of fuzzy partitions, Journal of Mathematical Analysis and Applications, Vol. 176, p. 359-373.

Greenhut J.G., Norman G., Temponi C.T. (1995), Towards a fuzzy theory of oligopolistic competition, IEEE Proceedings of ISUMA-NAFIPS, College Park, IEEE, p. 286-291.

Guixiang Wang, Cheng Lin Wen (2007), A new fuzzy arithmetic for discrete fuzzy numbers, Fourth International Conference on Fuzzy Systems and Knowledge Discovery, p. 52-56. 
Guixiang Wang, Qing Zhang, Xianjun Cui (2008), The discrete fuzzy numbers on a fixed set with finite support set, 2008 IEEE Conference on Cybernetics and Intelligent Systems, p. 812-817.

Gutierrez I. (1989), Fuzzy numbers and net present value, Scandinavian Journal of Management, Vol. 5(2).

Huang X. (2007), Risk curve and fuzzy portfolio selection, Int. J. Production Economics, Vol. 106, p. $1102-1112$.

Klir G.J. (1993), Developments In Uncertainty-based Information, [in:] M. Yovits (ed.), Advances in Computers, Vol. 36, Academic Press, San Diego, p. 255-332.

Knight F.H. (1964), Risk, uncertainty and profit, Reprints of Economic Classics, New York.

Kolmogorov A. (1956). Foundations of the Theory of Probability, New York, Chelsea.

Kuchta D. (2000), Fuzzy capital budgeting, Fuzzy Sets and Systems, Vol. 111, p. 367-385.

Lesage C. (2001), Discounted cash-flows analysis. An interactive fuzzy arithmetic approach, European Journal of Economic and Social Systems, Vol. 15(2), p. 49-68.

Markowitz H.S.M. (1952), Portfolio selection, Journal of Finance, Vol. 7, No. 1, p. 77-91.

Piasecki K. (2011), Behavioral Present Value, SSRN Electronic Journal, 01, DOI: 10.2139/ssrn.1729351.

Piasecki K., Siwek J. (2015), Behavioural Present Value defined as a fuzzy number - a new approach, Folia Oeconomica Stetinensia, p. 27-41, DOI: 10.1515/foli-2015-0033.

Sadowski W. (1980), Forecasting and decision making, Quantitative Wirtschafts - und Unternehmensforschung, Springer-Verlag, Berlin Heidelberg.

Siwek J. (2015a), Portfel dwuskładnikowy - przypadek wartości bieżącej danej trapezoidalna liczba rozmyta (w druku

Siwek J. (2015b), Portfel dwuskładnikowy - studium przypadku dla wartości bieżacej danej jako trójkątna liczba rozmyta, Studia Ekonomiczne. Zeszyty Naukowe Uniwersytetu Ekonomicznego w Katowicach, Vol. 141/2015, p. 140-150.

Tsao C.-T. (2005), Assessing the probabilistic fuzzy Net Present Value for a capital, Investment choice using fuzzy arithmetic, Journal of Chine Institute of Industrial Engineers, Vol. 22(2), p. 106-118.

Vicente Riera J., Torrens J. (2014), Aggregation functions on the set of discrete fuzzy numbers defined from a pair of discrete aggregations, Fuzzy Sets and Systems, Vol. 241, p. 76-93.

Vicente Riera J., Torrens J. (2015), Using discrete fuzzy numbers in the aggregation of incomplete qualitative information, Fuzzy Sets and Systems, Vol. 264, p. 121-137.

von Mises R. (1957), Probability, statistics and truth, The Macmillan Company, New York.

Voxman W. (2001), Canonical representation of discrete fuzzy numbers, Fuzzy Sets and Systems, Vol. 118, p. 457-467.

Ward T.L. (1985), Discounted fuzzy cash flow analysis, Fall Industrial Engineering Conference Proceedings, Berkeley, p. 476-481.

Wenyi Zeng, Qilei Feng, Hong Xing Li (2006), Relationship between inclusion measure and entropy of fuzzy sets, Springer-Verlag Berlin Heidelberg, RSKT, LNAI 4062, p. 333-340.

Zadeh L.A. (1965), Fuzzy sets, Information and Control, Vol. 8, p. 338-353.

\section{PORTFEL DWUSKŁADNIKOWY Z WARTOŚCIĄ BIEŻĄCĄ DANĄ LICZBĄ ROZMYTĄ O SKOŃCZONYM NOŚNIKU}

\section{Streszczenie}

Decyzje finansowe podejmowane przez inwestorów są obarczone ryzykiem. Przesłanki sugerują, że ma ono złożony charakter i może być rozpatrywane w kilku płaszczyznach. Ze względu na subiektywność wartości bieżącej oraz przesłanki behawioralne i techniczne przeprowadzono badania nad zwrotem z portfela dwuskładnikowego obarczonego ryzykiem nieprecyzyjności wyrażonej wartością bieżącą daną liczbą rozmytą o skończonym nośniku. W pracy pokazano oceny ryzyka 
wieloznaczności i nieostrości informacji obarczającej portfel oraz przedstawiono wyniki symulacji zachowania portfela w zależności od parametrów modelu. Podano też wnioski na temat zależności pomiędzy ryzykiem nieprecyzyjności a budową portfela.

Słowa kluczowe: portfel dwuskładnikowy, liczby rozmyte, nieprecyzyjność, wartość bieżąca

\title{
TWO-ASSET PORTFOLIO WITH PRESENT VALUE GIVEN BY A DISCRETE FUZZY NUMBER
}

\begin{abstract}
Summary
Financial decisions made by investors are burdened with risk. Known premises suggest, that this risk can have a complex character and should be considered at several levels. Because of the subjectivity of present value and behavioural and technological premises, research on a twoasset portfolio return encompassing the mentioned risks were performed. The article presents an analysis of a portfolio burdened by uncertainty and imprecision risk. Imprecision of information is reflected in asset's present value given as a discrete fuzzy number. Measures for uncertainty and imprecision risks are calculated by the means of energy and entropy. Also, simulation results for the portfolio under different parameter's values are presented. Based on performed analysis some conclusion about relations between imprecision risk and the structure of the portfolio are stated.
\end{abstract}

Keywords: two-asset portfolio, fuzzy numbers, imprecision, present value

\section{Aneks}

Kod programu Matlab dla programu liczącego $P V$, zwroty, wariancje, energie i entropie dla dwóch instrumentów o $P V$ danych skończonymi liczbami rozmytymi.

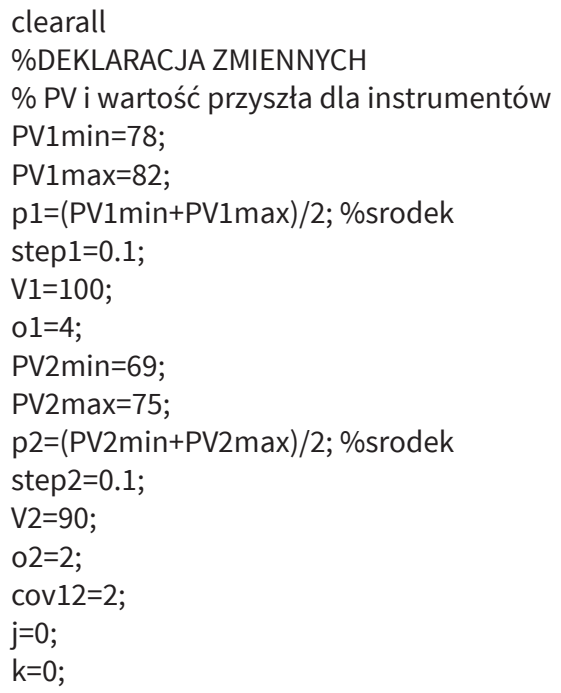


$\mathrm{a}=0$;

\% funkcje przynależności dla instrumentów - można zmieniać funkcje

for i=PV1min:step1:p1-step1

$j=j+1$;

$\operatorname{MI} 1(1, \mathrm{j})=\mathrm{i}$;

$\operatorname{MI}(2, j)=0.4995^{\star} i-38.96$;

end

for i=p1:step1:p1

$j=j+1$;

$\operatorname{MI}(1, \mathrm{j})=\mathrm{i}$;

$\operatorname{MI}(2, \mathrm{j})=1$;

end

for i=p1+step1:step1:PV1max

$\mathrm{j}=\mathrm{j}+1$;

$\operatorname{MI} 1(1, \mathrm{j})=\mathrm{i}$;

$\operatorname{MI} 1(2, j)=-0.4995^{\star} i+40.96$;

end

for i=PV2min:step2:p2- 21* step2

$\mathrm{k}=\mathrm{k}+1$;

$\operatorname{MI}(1, \mathrm{k})=\mathrm{i}$;

$M I 2(2, k)=0.999^{*} \mathrm{i}-68.93$;

end

for i=p2- 20* step2:step2:p2

$\mathrm{k}=\mathrm{k}+1$;

$M I 2(1, k)=i$;

$\operatorname{MI} 2(2, k)=1$;

end

for i=p2+step2:step2:PV2max

$\mathrm{k}=\mathrm{k}+1$;

$\operatorname{MI}(1, \mathrm{k})=\mathrm{i}$;

$\operatorname{MI} 2(2, k)=-0.333^{*} i+24.976$;

end

$\%$ KONIEC DEKLARACJI ZMIENNYCH

$\%$ zwroty z instrumentów + wykresy

$\mathrm{s}=0$;

for i=PV1min:step1:PV1max

$\mathrm{s}=\mathrm{s}+1$;

$\mathrm{r} 1=(\mathrm{V} 1-\mathrm{i}) / \mathrm{i}$;

$\mathrm{R} 1(1, \mathrm{~s})=\mathrm{r} 1$;

$\mathrm{R} 1(2, \mathrm{~s})=\mathrm{MI} 1(2, \mathrm{~s})$;

end

$\mathrm{t}=0$;

for $\mathrm{i}=\mathrm{PV} 2 \mathrm{~min}$ :step2:PV2max

$\mathrm{t}=\mathrm{t}+1$;

$\mathrm{r} 2=(\mathrm{V} 1-\mathrm{i}) / \mathrm{i}$;

$\mathrm{R} 2(1, \mathrm{t})=\mathrm{r} 2$;

$\mathrm{R} 2(2, \mathrm{t})=\mathrm{MI} 2(2, \mathrm{t})$;

end

figure

xlabel('r1')

ylabel('ro1(x)') 


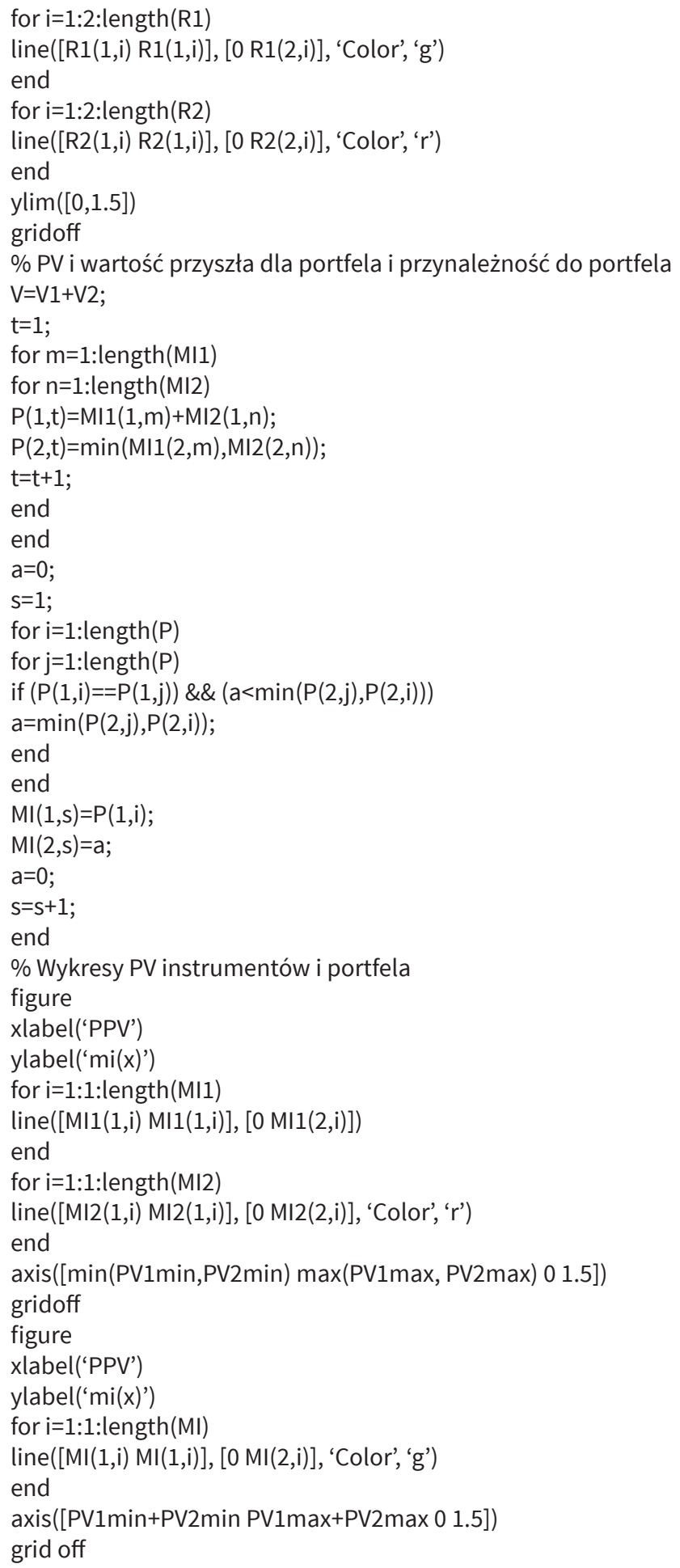




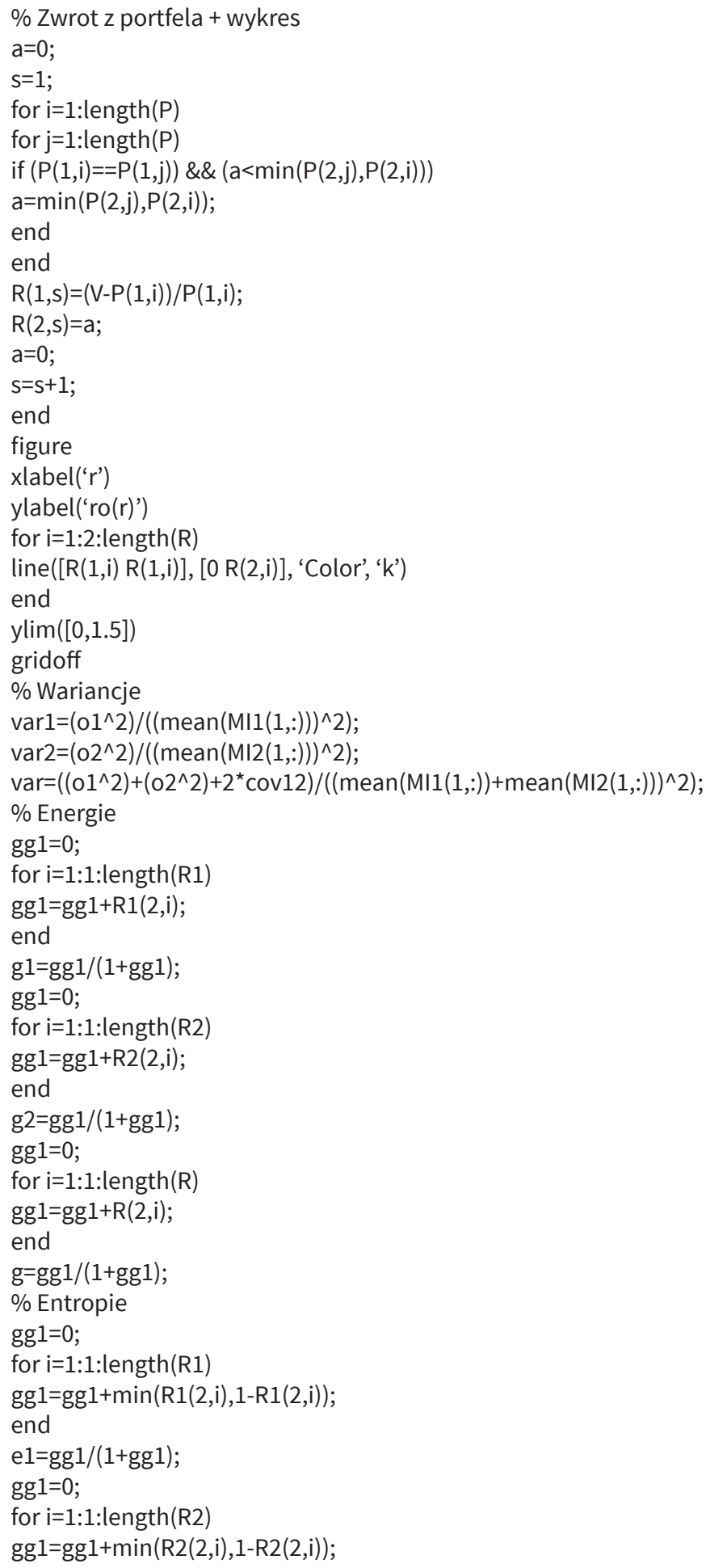


end

e2=gg1/(1+gg1);

gg1=0;

for $\mathrm{i}=1: 1$ :length(R)

$\operatorname{gg} 1=\operatorname{gg} 1+\min (\mathrm{R}(2, \mathrm{i}), 1-\mathrm{R}(2, \mathrm{i}))$;

end

e= $\operatorname{gg} 1 /(1+\operatorname{gg} 1)$;

\% Tabela wyników

display(,energie');

[g1 g2 g]

display('entropie');

[e1 e2 e]

display('wariancje');

[var1 var2 var] 